\title{
Development of an Artificial Multifunctional Foot: A Project Review
}

\author{
João Almeida ${ }^{\mathrm{a}, \mathrm{b}}$, Maria José Ferreira ${ }^{\mathrm{a}}$, Pedro Lobarinhas ${ }^{\mathrm{b}}$, Luís F. Silva ${ }^{\mathrm{b}}$, Abílio \\ Leite $^{c}$, Alfredo Araújo ${ }^{\mathrm{d}}$, Fernando Sousa ${ }^{\mathrm{d}}$ \\ ${ }^{a}$ Footwear Technology Centre of Portugal (CTCP), São João da Madeira, Portugal \\ ${ }^{b}$ Mechanical Engineering Department of the University of Minho, Guimarães, Portugal \\ ${ }^{c}$ Pegasil by Zipor, Equipments and Technology, SA, São João da Madeira, Portugal \\ ${ }^{d}$ Cei by Zipor, Equipments and Technology, SA, São João da Madeira, Portugal
}

\begin{abstract}
The main purpose of this project is the development of a multifunctional artificial foot, capable of duplicate a human foot in a laboratory environment, in order to evaluate and simulate footwear's performance under certain conditions. This foot is used as a laboratory prototype and is multisegmented, in order that each section is controlled independently in terms of heat generation and sweating rate, therefore it is possible to simulate more accurately the real behaviour of a human foot. The device produces thermal insulation values that will help to design footwear with better ability in terms of thermal comfort, replacing human volunteers in thermal comfort perception tests, which are very subjective. The prototype was already tested, and preliminary results indicated that thermal insulation values are within the range of expected values produced by other foot thermal manikins and by human volunteers' tests. This fact suggests that this lab prototype can be used infuture thermal comfort evaluations.
\end{abstract}

Keywords: Footwear testing, thermal comfort, lab prototype, sweating, thermal insulation.

\section{INTRODUCTION}

Human thermal regulation is mainly done by the extremities like feet and hands, thus footwear has an essential role in maintaining the thermal balance of the body (Strickland et al., 1997). The cold perception on feet has a correlation with low skin temperatures due to perspiration. The shoe may have a proper thermal insulation, but when the foot begins to get cold, it generates discomfort. In situations of low temperatures and high humidity, moisture will easily condensate, and this will induce a faster foot cooling (Taylor et al., 2006).Unfortunately, most of the footwear is quite impermeable to moisture in addition to a high thermal resistance, two factors that contribute to deep variations on the foot's skin temperature (Kuklane, 1999; Yuhong and Zhihua, 2001).

Several manikins have been developed over the last decades, and the first ones were built by the Royal Air Force (Fan et al, 2001) and by the US Army, for testing military garments (Hólmer, 1999; Nilsson, 2004; Goldman, 2006). More recently, a new generation of thermal sweating manikins like Walter, NEWTON, ADAM and SAM, are articulated and capable of simulating several positions, as well as monitoring real-time heat and water loss produced by sweating (Richards \& Mattle, 2001; Nilsson, 2004; Wang, 2008; Burke et al., 2009). Some foot manikins were also designed and developed like CYBOR (Uedelhoven\& Kurz, 1999), and the thermal sweating foots assembled by Kuklane (1999) and Yuhong \& Zhiua (2001), all of them multisegmented and able to reproduce variable sweating rates.However, there is still a lack of testing devices capable of realistically mimic thermo-physiological processes, thermal gradients of the extremities andsweating production and evaporation (Uedelhoven \& Kurz, 1999; McGuffin et al., 2002; Tamura, 2006). Furthermore these manikins are still very expensive to be built and its features are quite different depending on the lab/company in which they are being constructed/assembled, thus a method for an easy replication/standardization of these systems is yet to be achieved.

In this context, the design and development of a human foot prototype, capable of simulating thermal gradients and sweating rates close to the ones occurring physiologically in the human body, is of great importance and will bring an improvement in the process of testing footwear as well as developing and improving materials whose effect is important in the wet/wicked perception and consequently in the individuals' thermal comfort. The specific contributions and major advances of this work beyond the current state of the art in thermal foot manikins are its anthropometric shape and dimensions, which allow animproved fit between the tested footwear and the foot model and thus better replicating the real conditions occurring with human users. Another important advance of this foot manikin is that the sweating rates it is capable to mimics, vary within a wide range that has been estimated by tests with heterogeneous groups of human volunteers, with different ages and different physical conditions, in distinct

11th International Conference of Numerical Analysis and Applied Mathematics 2013 AIP Conf. Proc. 1558, 1394-1399 (2013); doi: 10.1063/1.4825776

(C) 2013 AIP Publishing LLC 978-0-7354-1184-5/\$30.00 
exercise/work conditions, thus the outcome of these tests were sweating rates much more realistic and accurate in a physiological way.

\title{
DEVELOPMENT
}

All the development of the project was divided in several stages, each one of them with its own degree of importance for achieving a final and complete version prototype working.

\section{Physiological Parameters Gathering}

\author{
Temperature Studies
}

The tests to evaluate the temperature gradient across the foot were performed with 8 volunteers ( 4 females and 4 males, aging between 25-42). 8 iButton ${ }^{\circledR}$ sensors were distributed equally over the feet (using 2 sensors in diametric opposite points on the foot's dorsal and 2 sensors in diametric opposite points adjacent to the foot's toes).

The subjects walked during 4 consecutive days, each one for a period of 60 minutes, wearing WOOK $^{\circledR}$ footwear. The final values approached to average values of $31,5{ }^{\circ} \mathrm{C}$ for temperature and $70 \%$ for relative humidity across the foot section.

\section{Sweating Studies}

A set of tests were designed using 8 individuals (again 4 females and 4 males, aging between 25-42) in order to evaluate and determinate average feet's sweating rates. These tests were made in 3 different conditions (during $8 \mathrm{~h}$ of continuous lab daily work; in periods of 15, 30 and 60 minutes, and during 30 minutes of cycling exercise), each one of these carried out during 4 consecutive days. The average environmental temperature and relative humidity for the tests was, respectively, $23{ }^{\circ} \mathrm{C}$ and $50 \%$.

Based on this values, it was decided to adopt an average sweating rate between $0,2-1,15 \mathrm{~g} / \mathrm{h}$ as a reference value.

\section{Laboratory Tests based on Obtained Evidences}

Using an aluminum bloc representative of a single prototype's segment, probes were taken in order to try to mimic the results obtained during the tests with human subjects. Following this goal, the bloc was drilled with 6 sweating terminals, fed by pipes connected to a peristaltic pump and heated by 2 heating flexible electrical resistors (total power $15 \mathrm{~W}$ ), controlled by 2 type-K thermocouples.

It was concluded that the heating elements should be fixed to fit the segment's geometry and that the most important element to assure an uniform temperature was the heating power (with a recommended power of $15 \mathrm{~W}$ ).

Several membranes were also tested to select the one whose behavior better matched the human's skin properties. The chosen membrane was a bilaminated membrane of $110 \mathrm{~g} / \mathrm{m}^{2}, 100 \%$ Jersey in the inner face and 100 $\%$ PU in the outer face, with a permeability of $3,76 \mathrm{mg} / \mathrm{cm}^{2}$. This membrane was selected because of its ability to absorb and spread uniformly the water and also to maintain a good heat balance.

\section{Specifications, Development and Assembly of the Final Prototype}

\section{Heating and Sweating Systems}

The heating system consists of controllers with PID control, a RS485-RS232 converter, solid-state relays, type-K thermocouples, heating flexible electrical resistors and an electrical feeding source, providing a total heating power of $103 \mathrm{~W}$.

The sweating system consists of a peristaltic pump with 16 channels and a set of 7 terminals fed by 7 PVC pipes divided into 4 independent zones. 


\section{Mechanical System}

The foot manikin was based in a model-shaped foot and built according anthropometric dimensions, after which it was submitted to a 3D scanning digitalization using the 3D Laser ZScanner ${ }^{\circledR}$, from DeltaCAD. The resulting file was then converted into a ${ }^{*}$.stl file type for a final SolidWorks ${ }^{\circledR}$ processing stage. After this stage all 7 segments were manufactured in a CNC machine using an aluminium alloy (Figure 1).

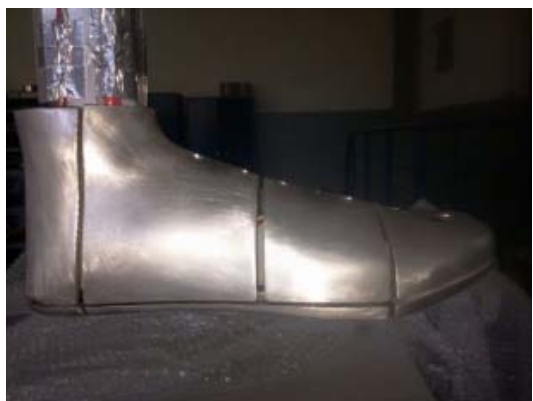

FIGURE 1. Final foot assembly with the 7 aluminium segments.

\section{Control System}

The control system represented in Figure 2 is capable to monitor and register the measurements of the thermocouples, to define the parameters for the tests and to enable the display of the results of the tests for further analysis. The control unit receives the inputs from the users parameters, introduced in the software, and the resultant outputs are send to the thermal foot manikin in order to simulate the selected thermal gradients and sweating rates.

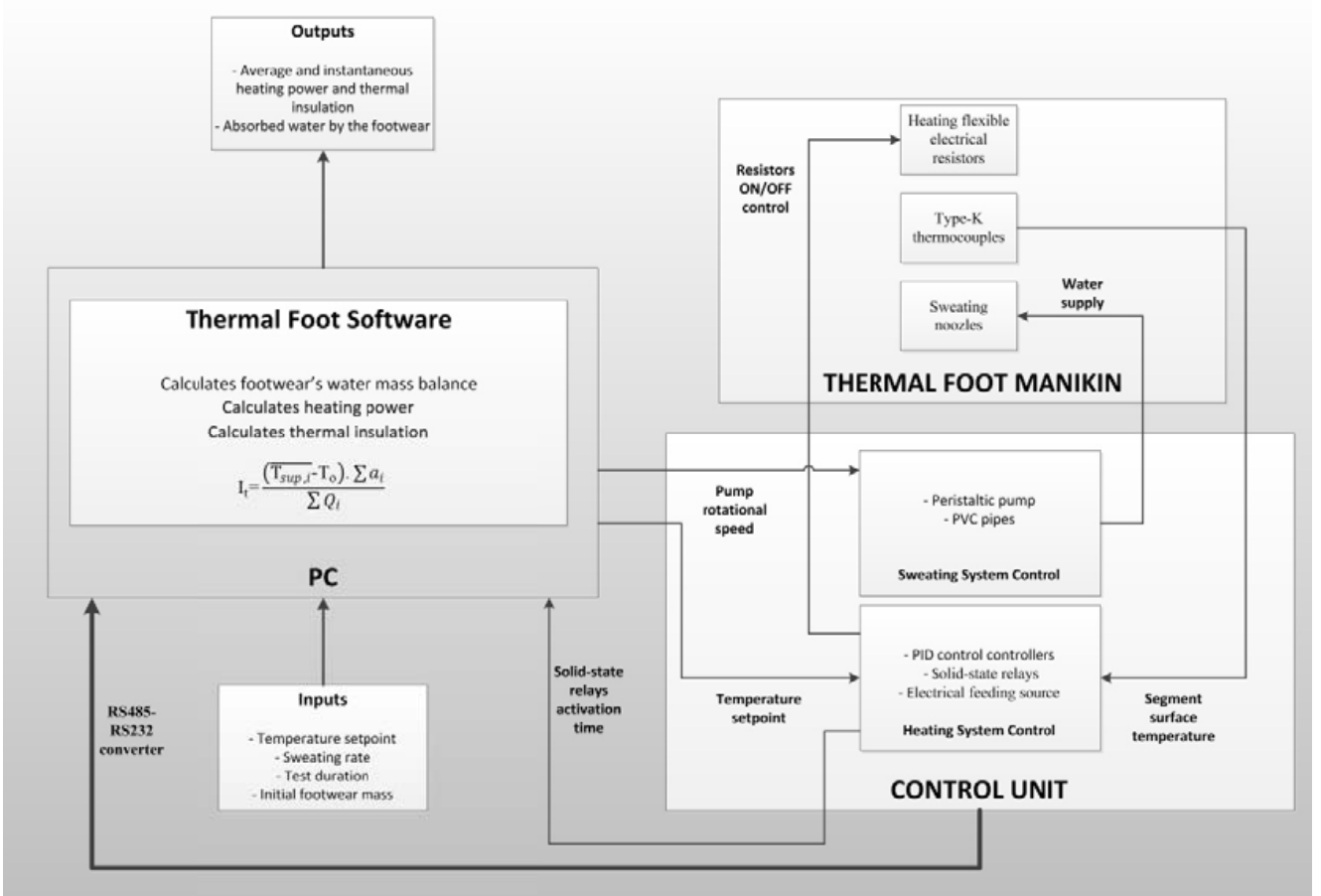

FIGURE 2. Block diagram of the control system.

The developed software also enables the user to carry out dry thermal insulation tests or thermal insulation and evaporative resistance tests, with sweating simulation. Before each test the user needs to introduce the footwear's 
thickness, height, duration of the test, temperature's setpoint and sweating rate. As output, the control system gives results for total and instantaneous local and global thermal insulation, water mass absorption and evaporation as well as local and global heating power dissipated.

\section{METHODS}

After testing and validating each one of the sub-systems independently, several tests were developed in order to compare the results obtained with the developed working model.

The experimental protocol used as a reference for the determination of the thermal insulation was adopted from the one proposedin a standard-project developed by Kalev Kuklane (2007). The general conditions adopted for the testswere the following:

- Air temperature: $5^{\circ} \mathrm{C} \pm 0,5^{\circ} \mathrm{C}$

- Relative humidity: 30-70\% $\pm 5 \%$

- Average superficial temperature of the manikin: $30-34{ }^{\circ} \mathrm{C}, \pm 0,3{ }^{\circ} \mathrm{C}$

- Three different footwear's models: WS boot, a warm boot of impregnated leather, with Thinsulate and nylon for insulation; AS boot, a leather boot without insulation layer; VS boot, a leather boot with an insulation layer of nylon

- $\quad$ Each model is to be tested in duplicated tests of 90 min each one

- The system starts the data acquisition when all the segments reach the same setpoint temperature

- In the tests with sweating simulation, the flow rate is $5 \mathrm{~mL} / \mathrm{h}$

The reasons for the adoption of this test protocol were to allow us to compare the performance of the developed testing (foot manikin) prototype with the results of the reference interlaboratory study (Kuklane et al, 2003), which is also based on the standard ISO 15831:2004.

For the whole foot, the parallel method for computing the thermal insulation was used (Equation 1), which assumes an uniform superficial temperature of the thermal manikin (all the heating power, temperatures and segment areas are summed before its calculation):

in which,

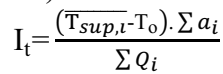

$\mathrm{I}_{\mathrm{i}}=$ thermal insulation of the segment $\mathrm{i}\left[\mathrm{m}^{2} .{ }^{\circ} \mathrm{C} / \mathrm{W}\right]$

$\mathrm{T}_{\text {sup }, \mathrm{i}}=$ average temperature on segment $\mathrm{i}$ during the test $\left[{ }^{\circ} \mathrm{C}\right]$

$\mathrm{T}_{0}=$ average air temperature during the test $\left[{ }^{\circ} \mathrm{C}\right]$

$\mathrm{a}_{\mathrm{i}}=$ area of segment $\mathrm{i}\left[\mathrm{m}^{2}\right]$

$\mathrm{Q}_{\mathrm{i}}=$ heating power consumed by segment $\mathrm{i}[\mathrm{W}]$

\section{RESULTS AND DISCUSSION}

As observed in Figure 3, the thermal insulation of the WS boot $\left(0,24 \mathrm{~m} 2 .{ }^{\circ} \mathrm{C} / \mathrm{W}\right)$, the only model for which any comparison can be made with the results obtained in the interlaboratory tests, is within the range of reference values $\left(0,24-0,31 \mathrm{~m} 2 .{ }^{\circ} \mathrm{C} / \mathrm{W}\right)$, for the set of experiments 1 . However, for the set of experiments 2 , there was a decrease in the measured values for all the boot models. 


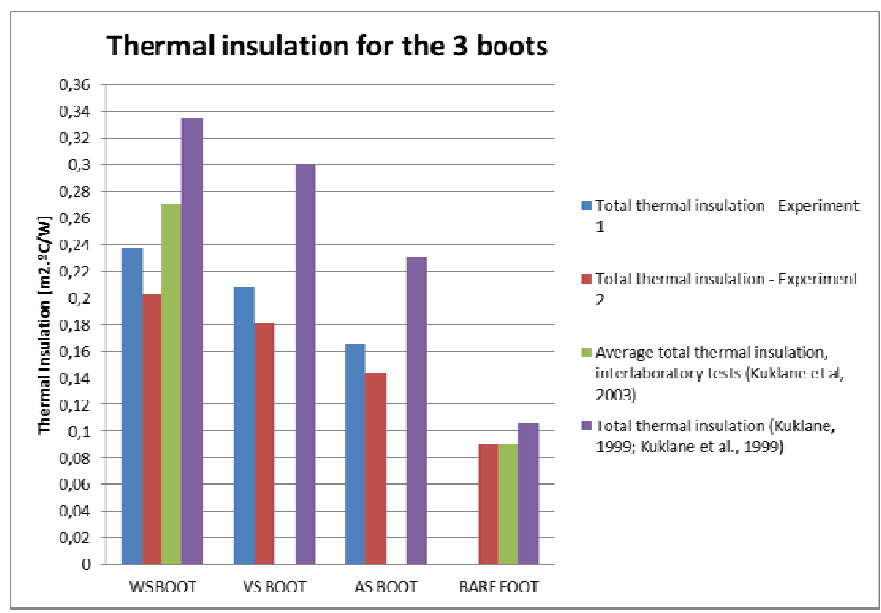

FIGURE 3. Thermal insulation results for the three boot models, tested in two sets of experiments: a comparison is carried out with the interlaboratory tests and Kuklane tests.

Comparing the 3 boot models (Figure 4) it is possible to observe that the measurements are reproducible and that there is an internal coherence between all the values ( $I_{\text {tot }} A S<I_{\text {tot }} V S<I_{\text {tot }}$ WS), for both set of experiments.

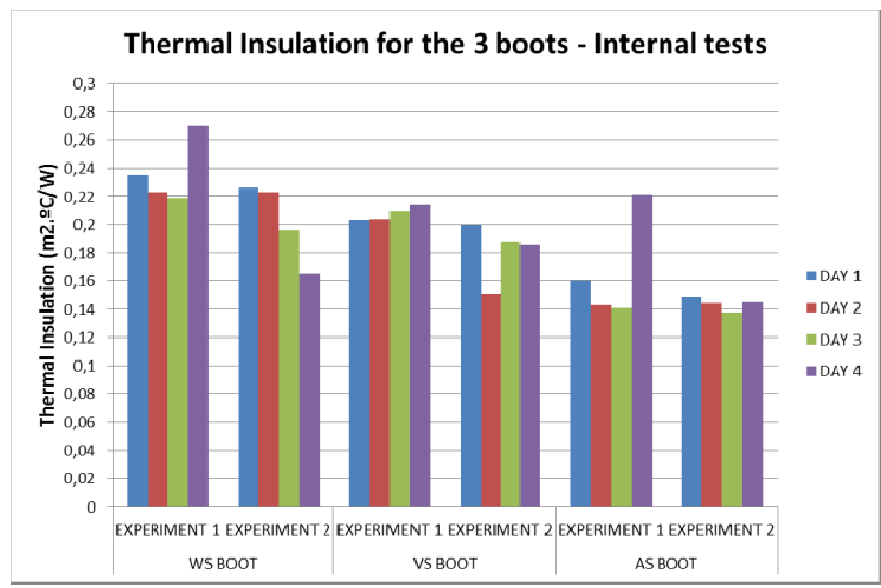

FIGURE 4. Thermal insulation comparison for the three boot models, in the two sets of internal experiments.

The variations of the environmental temperature conditions during the tests could be responsible for the variations in the thermal insulation values, either internally (between the experiments 1 and 2) or comparing them with the interlaboratory tests. Following this hypothesis, comparisons were made between the thermal insulation of each boot, and the environmental temperature the test was performed. Taken the example of the WS boot, (Figure 4), the highest thermal insulation value $\left(0,225 \mathrm{~m}^{2} .{ }^{\circ} \mathrm{C} / \mathrm{W}\right)$ was obtained at $4,7^{\circ} \mathrm{C}$ (Day 1 - Experiment 2$)$, while the lowest value $\left(0,16 \mathrm{~m}^{2} .{ }^{\circ} \mathrm{C} / \mathrm{W}\right)$ was obtained at $7,5^{\circ} \mathrm{C}$ (Day 4 - Experiment 2 ).

This finding is very important because it confirms the need of a rigorous control of the environmental conditions during the tests, particularly of the temperature, in order to achieve thermal insulation values more accurate and representative.

\section{SUMMARY AND CONCLUSIONS}

The novel aspects of this prototype, comparing it with other similar models already developed, are its anthropometric shape and dimensions, which make these tests much more realistic and accurate. An analysis of the results enable us to conclude that the designed and developed system is capable of producing reproducible results 
within the range of expectable values, according to the interlaboratory reference tests and approaching the results obtained with human volunteers.

Despite the favorable results, these tests require a more accurate and complete approach, once each partner/entity of the interlaboratory tests have distinct issues related to the acquisition/processing methods, temperature and heating power calculations, so the outcome of thermal insulation's values may have considerable intrinsic variations between each one of the results. This is very important in order to guarantee a rigorous comparison and validation of obtained data.

It is also recommended to repeat the tests increasing the number of replications, in order to eliminate error factors like heating system stabilization and changes in environmental temperature and relative humidity conditions, which, as it has been demonstrated, are very important sources of uncertainty in the thermal insulation measures.

\section{REFERENCES}

1. Burke, R., Curran, A., Hepokoski, M., - Integrating an Active Physiological and Comfort Model to the Newton Sweating Thermal Manikin. In Proceedings of the $13^{\text {th }}$ International Conference on Environmental Ergonomics - Boston, USA, 2009.

2. Fan, J., Chen, Y., Zhang, W., - A Perspiring Fabric Thermal Manikin: Its Development and Use. In Proceedings of the Fourth International Meeting on Thermal Manikins - EMPA Switzerland, 2001.

3. Goldman, R.F., - Thermal Manikins, their Origins and Role. In Proceedings of the $6^{\text {th }}$ International Thermal Manikin and Modelling Meeting - Hong Kong, 2006.

4. Holmér, I. - Thermal manikins in research and standards. In Proceedings of the Third International Meeting on Thermal Manikin Testing, 1999.

5. ISO 15831, 2004 - Measurement of thermal insulation by means of a thermal manikin. ISO.

6. Kuklane, K., 1999. Footwear for cold environments: Thermal properties, performance and testing, Lulea University of Technology.

7. Kuklane, K. et al, 2003. "Interlaboratory tests on thermal foot models", Thermal Environment Laboratory, EAT report, Lund University, Sweden.

8. Kuklane,K., 2007 "Standard test method for measuring the thermal insulation and evaporative resistance of footwear using a heat foot model", Thermal Environmental Laboratory, Lund Institute of Technology, Sweden.

9. Mcguffin, R., Burke, R., Huizenga, C., Hui, Z., Vlahinos, A., Fu, G. - "Human Thermal Comfort Model and Manikin".Society of Automotive Engineers, 2002.

10. Nilsson, H., - Comfort Climate Evaluation with Thermal Manikin Methods and Computer Simulation Models. Royal Institute of Technology, Sweden, 2004.

11. Richards, M., Mattle, N. - Development of a sweating agile thermal manikin (SAM).InProceedings of the Fourth International Meeting on Thermal Manikins - EMPA Switzerland, 2001.

12. Strickland, P., Reid, G., Burrows, B., 1997. "Thermal Profiles in Footwear Design: An in-sole measurement system", 4th Annual Conference on Mechatronics and Machine Vision in Practice, Toowoomba, Australia.

13. Taylor, N.A.S; Caldwell, J.N.; Mekjavic, I.B.,2006. "The Sweating Foot: Local Differences in Sweat Secretion During Exercise-Induced Hyperthermia", Aviation, Space and Environmental Medicine, Vol. 77, $\mathrm{n}^{\circ} 10$.

14. Uedelhoven, W., Kurz, B., "CYBOR sweating concept”, 1999.

15. Wang, F., - A Comparative Introduction on Sweating Thermal Manikin Newton and Walker. In $7^{\text {th }}$ International Thermal Manikin and Modelling Meeting - Coimbra, Portugal, 2008.

16. Yuhong, S. and Zhihua, J., 2001. "Measurement and evaluation of heat-moisture comfort of footwear", Proceedings of the Fourth International Meeting on Thermal Manikins, EMPA Switzerland. 